\title{
RELATION BETWEEN SERUM MAGNESIUM AND DIABETIC NEPHROPATHY
}

Ketham Veera Sudhakar *1, Mohammed Sabiullah ${ }^{2}$, A. Padma Vijaya Sree ${ }^{3}$, B. Vijaya Saradhini ${ }^{4}$, P. V. Satyanarayana ${ }^{5}$, Venateswarlu ${ }^{3}$, Aparna ${ }^{3}$.

${ }^{* 1}$ Department of Biochemistry, V iswabharathi Medical College \& General Hospital, Kurnool, Andhra Pradesh, India.

2 Department of Biochemistry, Osmania Medical College, Hyderabad, India.

${ }^{3}$ Department of Biochemistry, Kurnool medical college, Kurnool, Andhra Pradesh, India.

${ }^{4}$ Joint Director (Medical) O/o. Directorate of Medical Education, Hyderabad, India.

${ }^{5}$ The Controller of Examinations, Kalojinarayana Rao University of Health Sciences, Warangal, Telangana, India.

\section{ABSTRACT}

Introduction: Hypomagnesemia leads to platelet agregability and also decreased function of magnesium dependant enzymes, kinases and channels regulating insulin action leading to complications, and oxidative stress is also seen because of hyperglycemia. Hence we studied the serum magnesium in patients with diabetic nephropathy.

Materials and Methods: The present study was carried out on 30 diabetic nephropathy patients, 30 normal healthy controls from government General hospital, Kurnool. $5 \mathrm{ml}$ of blood is collected and centrifuged and analyzed in the same day.

Results: HbA1c level were statistically significantly increased (cases $9.04 \pm 1.34 \%$ and in the controls $5.95 \pm$ $0.14 \%$ and $\mathrm{P}<0.001$ ) in diabetic nephropathy patients. to contrast to this the serum $\mathrm{Mg}$ levels were statistically significantly decreased in the diabetic nephropathy patients (Cases $1.66 \pm 0.20 \mathrm{mg} / \mathrm{dl}$; controls $2.25 \pm 0.15 \mathrm{mg}$ / $\mathrm{dl}$ and $\mathrm{P}<0.001)$.

Conclusions: This $\mathrm{Mg}$ depletion is said to have a negative impact on glucose homeostasis and insulin sensitivity in diabetic nephropathy patient as well as on the development \& progression of diabetic nephropathy. Early diagnosis \& prompt treatment of the diabetic nephropathy can improve the quality of life \& increase life expectancy. KEY WORDS: Mg, HbA1C, FBS, Diabetic nephropathy.

Address for correspondence: Dr. Ketham Veera Sudhakar, Department of Biochemistry, Viswabharathi Medical College \& General Hospital, Kurnool, Andhra Pradesh, India.

E-Mail: sudhakarketham.md@gmail.com

\begin{tabular}{|c|c|c|}
\hline \multicolumn{3}{|c|}{ Online Access and Article Informtaion } \\
\hline \multirow{2}{*}{ Quick Response code } & \multicolumn{2}{|c|}{$\begin{array}{l}\text { International Journal of Integrative Medical Sciences } \\
\text { www.imedsciences.com }\end{array}$} \\
\hline & $\begin{array}{l}\text { Received: } 20-02-2018 \\
\text { Reviewed: } 21-02-2018\end{array}$ & $\begin{array}{l}\text { Accepted: } 15-03-2018 \\
\text { Published: } 31-03-2018\end{array}$ \\
\hline Source of Funding: Self & \multicolumn{2}{|c|}{ Conflicts of interest: None } \\
\hline
\end{tabular}

\section{BACKGROUND}

Magnesium is the fourth most abundant cation is present in 3 states-ionized (62\%), protein bound (30\%) mainly to albumin, and complexed to anions such as citrate and phosphate, only less than $1 \%$ of total body, is distributed principally between bone (53\%), muscle $(27 \%)$ and soft tissue (19\%) [1]. Serum magnesium comprises only about $0.3 \%$ of total magnesium where it [1]. Rich sources of magnesium in the diet 
include cereals and legumes. Magnesium absorption occurs principally from the ileum and colon. Excretion of magnesium occurs via the kidney. Magnesium is intimately involved in over 300 enzymatic reactions, particularly in processes involving the formation and utilization of ATP. It also has an important endocrine function and is required for protein synthesis. Magnesium has an essential role in the function of cell membrane sodium-potassium ATPase pump [2]. Magnesium is an obligate ion that is essential for the activation of many enzymes like the enzymes involved in glucose metabolism, fatty acid synthesis, and DNA and protein metabolism. In addition, magnesium is required for the activity of adenylate cyclase, which transmits extracellular hormonal signals to the intracellular apparatus. It also has a role in muscle contraction, neuronal activity, and control of vasomotor tone, cardiac excitability and neurotransmitter release [3].

$13.5-47.7 \%$ incidence of Hypomagnesemia among patients with diabetes mellitus [4]. The exact cause of hypomagnesemia in diabetics is not known. Poor dietary intake, autonomic dysfunction, altered insulin metabolism, glomerular hyperfiltration, osmotic diuresis, recurrent metabolic acidosis, hypophosphatemia and hypokalemia may be contributory. Although diabetes mellitus can induce hypomagnesemia, magnesium deficiency has also been proposed as a risk factor for type 2 diabetes mellitus. Some short term metabolic studies suggest that magnesium supplementation has a beneficial effect on insulin action and glucose metabolism [5]. In two cross-sectional studies found Patients with diabetic nephropathy had lower serum magnesium levels when compared with their counterparts, and serum magnesium levels among the patients with diabetes mellitus had an inverse correlation with the degree of nephropathy. With this background the present study is carried out to assess serum magnesium in patients with diabetic nephropathy.

\section{MATERIALS AND METHODS}

Study design: This case control study was conducted.

Setting: This study was conducted at Biochemistry department with collaboration with Neph rology department. We included A total of 60 (30 diabetic nephropathy patients, and 30 healthy controls) age and sex matched subjects were participated in the study by giving informed consent form from government General hospital, Kurnool. Patients with chronic renal failure, glomerular nephritis due to other systemic conditions and hypertensives were excluded from the study.

Sample collection and analysis: After an overnight fast of 12 to $14 \mathrm{hrs}, 5 \mathrm{ml}$ blood was collected by veni puncture. $3 \mathrm{ml}$ of blood was collected in anticoagulant (EDTA and fluoride) vacutainer. The remaining $3 \mathrm{ml}$ is taken into another bottle and allowed to clot. Serum and plasma were separated. The Fasting blood sugar by GOD-POD method and Glycated Hemoglobin by Micro column method on RA- 50 instrument, and Serum magnesium estimated by Calmagite method were estimated on the same day on.

Statistical analysis: All values obtained will be expressed as Mean ( \pm SEM). Unpaired two-tailed student $t$-test will be performed to compare the difference in the means between controls and study group. A ' $P$ ' value $<0.05$ will be considered as statistically significant. Statistical Analysis will be done by using Microsoft excel spread sheets.

\section{RESULTS}

A total number of 60 subjects, 30 healthy controls (Males: 18,and Females : 12) and 30 cases (Diabetic nephropathy subjects: Males : 19, and Females : 11) were include in the study.

Table 1: Shows comparison of fasting blood glucose and Glycosylated haemoglobin (HbA1c) in between cases and controls.

\begin{tabular}{|c|c|c|c|c|c|}
\hline \multirow{2}{*}{} & \multicolumn{2}{|c|}{ Cases } & \multicolumn{2}{c|}{ Control } & \multirow{2}{*}{ P value } \\
\cline { 2 - 5 } & Mean & SD & Mean & SD & \\
\hline FBS & 182.43 & 13.63 & 92.77 & 4.38 & $<0.001$ \\
\hline HBA1C & 9.04 & 1.34 & 5.95 & 0.14 & $<0.001$ \\
\hline
\end{tabular}

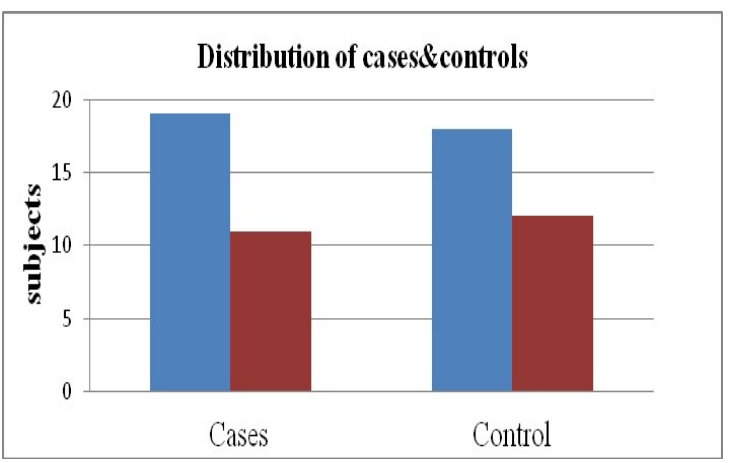


Table 2: Shows comparison of mean serum magnesium levels between cases and controls.

\begin{tabular}{|c|c|c|c|c|c|}
\hline \multirow{2}{*}{} & \multicolumn{2}{|c|}{ Cases } & \multicolumn{2}{c|}{ Control } & \multirow{2}{*}{ P value } \\
\cline { 2 - 5 } & Mean & SD & Mean & SD & \\
\hline Mg & 1.66 & 0.2 & 2.26 & 0.15 & $<0.001$ \\
\hline
\end{tabular}

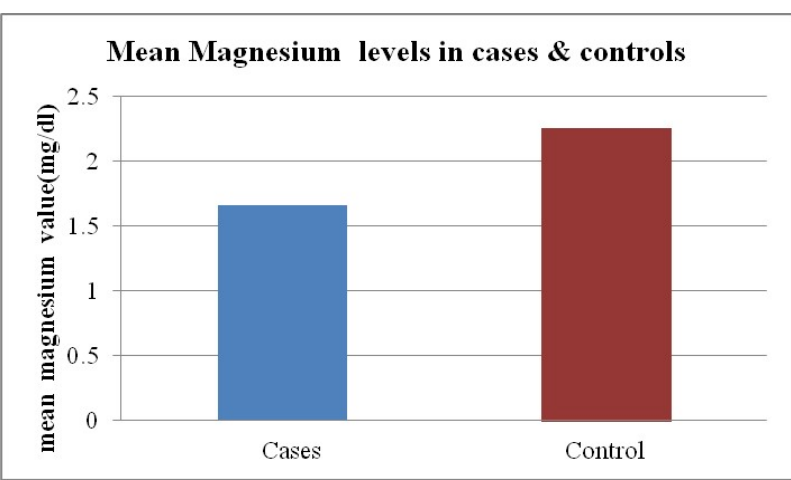

Table 3: Shows the correlation of FBS, $\mathrm{HbA1C}$ and $\mathrm{Mg}$.

\begin{tabular}{|c|c|c|c|c|}
\hline & & FBS & HbA1c & Mg \\
\hline \multirow{2}{*}{ FBS } & $r$ & & 0.2 & -0.21 \\
\cline { 2 - 5 } & $P$ & & 0 & 0 \\
\hline \multirow{2}{*}{ HbA1c } & $r$ & 0.2 & & -0.09 \\
\cline { 2 - 5 } & $P$ & 0 & & 0 \\
\hline
\end{tabular}

\section{DISCUSSION}

Hypomagnesemia is a series of risk factor have been related to the development and progression of diabetic nephropathy, were more prone for complications. In this study, 60 subjects 30 healthy controls (Males: 18, and Females: 12) and 30 cases (Diabetic nephropathy subjects: Males: 19, and Females: 11) and estimated serum magnesium levels were studied in both groups. The mean and SD of fasting blood sugar level were cases $182.43- \pm 13.63 \mathrm{mg} / \mathrm{dl}$, controls $92.77 \pm 4.38 \mathrm{mg} / \mathrm{dl}$, and Glycated haemoglobin level in cases $9.04 \pm 1.34 \%$ and in the controls $5.95 \pm 0.14 \%$ were also statistically significantly increased ( $P<0.001$, and $<0.001$ respectively) in diabetic nephropathy patients when compared with healthy controls. Our findings are comparable with the previous studies done by Meigs $\mathrm{jb}$ et al, (6) who have found that there was a significant association between FBS levels with the severity of diabetic nephropathypathy, and Nathan DM et al, [7] who also observed increased $\mathrm{HbA} 1 \mathrm{c}$ levels in diabetic nephropathy patients when compared to the control group.The findings of the present study and the previous studies show that hyperglycemia, as indicated by the increase in the FBS and $\mathrm{HbA} 1 \mathrm{c}$ levels, is a potent predictor of progression of diabetic nephropathy [8]. The possible mechanism is hyperglycemia leads to glycation of virtually all proteins, resulting in the formation of advanced glycation end products [9]. These advanced glycation end products induce cross linking of collagen and other extracellular matrix proteins in many tissues including arterial vessel walls [10]. Hyperglycemia-induced vascular injury leads to increased glucose flux through the polyol pathway, resulting in cellular damage, thereby resulting in the various micro vascular and macro vascular complications. HbA1c is also shown to have a special affinity for oxygen thereby causes tissue anoxia and plays a role in causation of micro and macroangiopathy. The interaction of advanced glycation end products and their receptors have been implicated as mediators of micro vascular permeability, ischemia \& angiogenesis [11].

In the present study, the Mean \pm SD of serum magnesium level in Cases $(1.66 \pm 0.20 \mathrm{mg} / \mathrm{dl})$ were decreased when compared with healthy controls $(2.25 \pm 0.15 \mathrm{mg} / \mathrm{dl})$, statistically significant $(P<0.001)$. Similar findings found in studies done by Corsenello A et al, [12] have shown the presence of hypomagnesemia in diabetic nephropathy. The FBS and $\mathrm{HbA1c}$ were significantly positively correlated $(r=0.20$, $\mathrm{p}=0.00$ ), and but both FBS and $\mathrm{HbA1c}$ were significantly negatively correlated with $\mathrm{Mg}$ $(r=-0.21, p=0.00$ and $r=-0.09$, and $p=0.00)$ respectively.

Hypomagnesemia in patients with type 2 diabetes mellitus is very common. The exact cause of hypomagnesemia in diabetic nephropathy is not known, but an increased urinary loss of $\mathrm{Mg}$ may contribute to it [13]. Some studies revealed that hyperglycemia contribute to hypomagnesemia by causing depression in the net tubular reabsorption of $\mathrm{Mg}[14,15]$. Hence, $\mathrm{Mg}$ has been reported to possess antioxidant property, oxidative stress may be one of the mechanisms that underlie the association between low serum Mg [16]. Study has also shown that $\mathrm{Mg}$ intake and serum $\mathrm{Mg}$ concentration were inversely associated with systemic inflammation markers, which also play a crucial role in the pathogenesis of Microalbuminuria $[17,18]$. Poor dietary intake, impaired absorption of magnesium, increased urinary loss due 
to hyperglycemia and osmotic diuresis may be the contributory factors. Magnesium is necessary for several enzymes that play an important role in glucose metabolism. Magnesium depletion is said to reduce the insulin sensitivity, thereby increasing the risk of secondary complications $[19,20]$. Hence it is important to monitor the plasma magnesium levels in diabetic nephropathy patients. Magnesium supplementation may help to reduce the progression of nephropathy in these patients. Early diagnosis and prompt treatment in these patients can reduce the onset and progression of nephropathy. Further studies with oral magnesium supplementation in different stages of diabetic nephropathy can be interesting.

\section{CONCLUSION}

Based on the results of the present study and data available from literature, it can be implicated that $\mathrm{HbA1C}$, hypomagnesemia were involved in the development of diabetic nephropathy. $\mathrm{HbA} 1 \mathrm{c}$ levels are found to be the potent predictor's of progression of diabetic nephropathy. Hyperglycemia leads to the formation of advanced glycation end products, which result in the development\& progression of diabetic nephropathy. Along with this Magnesium depletion is said to have a negative impact on glucose homeostasis and insulin sensitivity in diabetic nephropathy patient as well as on the development \& progression of diabetic nephropathy. From the results of the present study, it can be concluded that estimation of HbA1c, serum magnesium, can help us to predict the onset and progression of diabetic nephropathy and prevent development of end stage renal disease which is a major cause of morbidity and mortality in diabetic nephropathy patients. Early diagnosis \& prompt treatment of the diabetic nephropathy can improve the quality of life \& increase life expectancy.

\section{REFERENCES}

[1]. Saris NE, Mervaala E, Karppanen H, Khawaja JA, Lewenstam A. Magnesium. An update on physiological, clinical and analytical aspects. Clin Chim Acta 2000; 294: 1-26.

[2]. Ryan MF. The role of magnesium in clinical biochemistry: an overview. Ann Clin Biochem 1991; 28: 19- 26.

[3]. Rao PP, Shariff MG. Serum Magnesium Levels in Type
2 Diabetic Patients with Microalbuminuria and Normoalbuminuria. Int J Sci Stud 2015;3(4):11-15.

[4]. Pham PC, Pham PM, Pham SV, Miller JM, Pham PT. Hypomagnesemia in patients with type 2 diabetes. Clin J Am Soc Nephrol. 2007;2(2):366-73.

[5]. Emila.S and Swaminathan. S. Role of Magnesium in Health and Disease. Journal of Experimental Sciences 2013;4(2):32-43..

[6]. Meigs JB, Mittleman MA, Nathan DM, Tofler GH, Singer DE, Murphy-Sheehy PM, et.al,. Hyperinsulinemia, hyperglycemia, and impaired hemostasis: the Framingham Offspring Study. JAMA. 2000;283(2):221-8.

[7]. Nathan DM, Singer DE, Hurxthal K, Goodson JD. The clinical information value of the glycosylated haemoglobin assay. N. Engl J Med. 1984;310:341-6.

[8]. Ezra Belay Ketema, Kelemu Tilahun Kibret. Correlation of fasting and postprandial plasma glucose with $\mathrm{HbA1c}$ in assessing glycemic control; systematic review and meta-analysis. Arch Public Health. 2015;73:43.

[9]. Helen Vlassara, Jaime Uribarri. Advanced Glycation End Products (AGE) and Diabetes: Cause, Effect, or Both? Curr Diab Rep. 2014;14(1):453.

[10]. Kerstin Nowotny, Tobias Jung, Annika Höhn, Daniela Weber, Tilman Grune. Advanced Glycation End Products and Oxidative Stress in Type 2 Diabetes Mellitus. Biomolecules. 2015;5(1):194-222.

[11]. Aastha Chawla, Rajeev Chawla, Shalini Jaggi. Microvasular and macrovascular complications in diabetes mellitus: Distinct or continuum? Indian J Endocrinol Metab. 2016; 20(4):546-51.

[12]. Corsonello A, lentile R, Buemi M, Cucinotta $D$, Mauro VN, Macaione $S$, et al. Serum ionized magnesium levels in type 2 diabetic patients with microalbuminuria or clinical proteinuria. Am J Nephrol 2000; 20: 187-192.

[13]. Rao PP, Shariff MG. Serum Magnesium Levels in Type 2 Diabetic Patients with Microalbuminuria and Normoalbuminuria. Int J Sci Stud 2015;3(4):11-15.

[14]. McCarty MF. Magnesium may mediate the favorable impact of whole grains on insulin sensitivity by acting as a mild calcium antagonist. Med Hypotheses 2005;64:619-27.

[15]. Mandon B, Siga E, Chabardes D, Firsov D, Roinel N, De Rouffignac C. Insulin stimulates $\mathrm{Na}+, \mathrm{Cl}-, \mathrm{Ca} 2+$, and $\mathrm{Mg} 2+$ transports in TAL of mouse nephron: Cross-potentiation with AVP. Am J Physiol 1993;265:361-9.

[16]. Altura BT, Altura BM. Endothelium-dependent relaxation in coronary arteries requires magnesium ions. Br J Pharmacol 1987;91:449-51.

[17]. Kim DJ, Xun P, Liu K, Loria C, Yokota K, Jacobs DR Jr, et al. Magnesium intake in relation to systemic inflammation, insulin resistance, and the incidence of diabetes. Diabetes Care 2010;33:2604-10.

[18]. Mirrahimi B, Hamishehkar H, Ahmadi A, Mirjalili MR, Agamohamadi M, Najafi A, et al. The efficacy of magnesium sulfate loading on microalbuminuria following SIRS: One step forward in dosing. Daru 2012;20:74. 
[19]. Emila. S, Swaminathan. S. Role of Magnesium in Health and Disease. Journal of Experimental Sciences 2013, 4(2): 32-43.

[20]. Sushma S, Devi MSK, Naveen S. The Study of Relationship Between Serum Magnesium and Glycated Hemoglobin in Clinically Uncomplicated Type-2 Diabetes Mellitus Patients. J Health Sci Res 2015;6(1);14.

How to cite this article: Ketham Veera Sudhakar, Mohammed Sabiullah, A. Padma Vijaya Sree, B. Vijaya Saradhini, P. V. Satyanarayana, Venateswarlu, Aparna. RELATION BETWEEN SERUM MAGNESIUM AND DIABETIC NEPHROPATHY. Int J Intg Med Sci 2018;5(3):597-601. DOI: 10.16965/ijims.2018.105

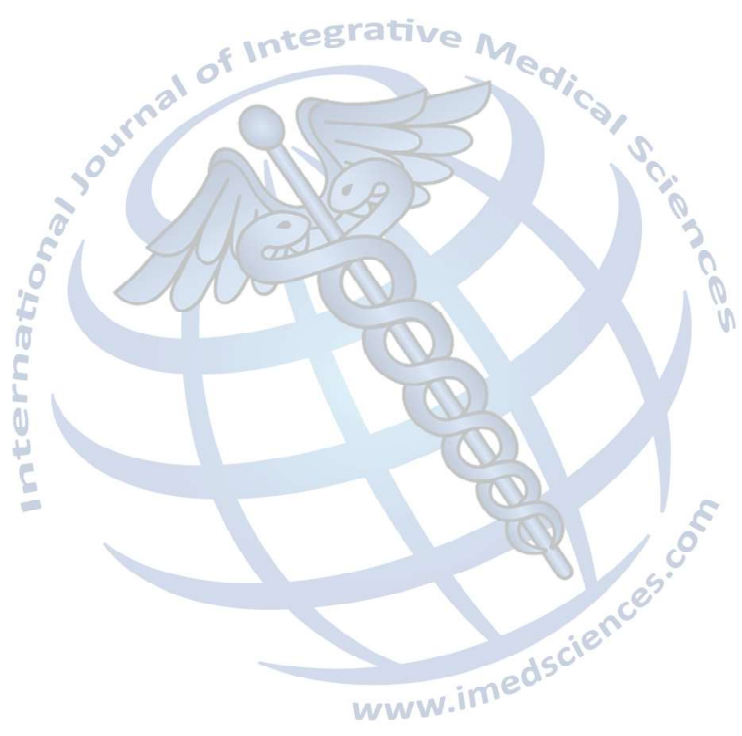

